\title{
Norois
}

Environnement, aménagement, société

\section{Introduction : éléments pour une nouvelle géographie des campagnes}

Olivier David et Valérie Jousseaume

\section{(2) OpenEdition}

\section{Journals}

Édition électronique

URL : http://journals.openedition.org/norois/1598

DOI : $10.4000 /$ norois. 1598

ISBN : 978-2-7535-1550-5

ISSN : $1760-8546$

Éditeur

Presses universitaires de Rennes

Édition imprimée

Date de publication : 1 mars 2007

Pagination : 7-8

ISBN : 978-2-7535-0457-8

ISSN : 0029-182X

\section{Référence électronique}

Olivier David et Valérie Jousseaume, «Introduction : éléments pour une nouvelle géographie des

campagnes », Norois [En ligne], 202 | 2007/1, mis en ligne le 01 mars 2007, consulté le 19 avril 2019.

URL : http://journals.openedition.org/norois/1598; DOI : 10.4000/norois.1598

(c) Tous droits réservés 


\title{
INTRODUCTION :
}

\section{ÉLÉMENTS POUR UNE NOUVELLE GÉOGRAPHIE DES CAMPAGNES}

\author{
Olivier DAVID \\ RESO - UMR ESO 6590 CNRS \\ (Université de Rennes 2 Haute-Bretagne), Maison de la Recherche en Sciences sociales, \\ Place du Recteur H. Le Moal, CS 24307 - 35043 RenNES cedex \\ olivier.david@uhb.fr \\ VALÉrie JousSEAume \\ CESTAN - UMR ESO 6590 CNRS \\ (Université de Nantes), \\ Campus du Tertre, BP 81227 - 44312 NANTES cedex 03 \\ valerie.jousseaume@univ-nantes.fr
}

Au cours des six dernières décennies, de multiples transformations démographiques, sociales et économiques ont profondément bouleversé l'organisation des campagnes du monde occidental. L'ampleur des mutations, et la rapidité à laquelle elles se sont opérées, ont donné naissance à de nouvelles réalités rurales. Dans le même temps, le regard porté sur ces campagnes s'est élargi et enrichi de nouvelles approches et de nouveaux paradigmes scientifiques. Organisé par l'Unité mixte de recherche "Espaces géographiques et Sociétés », le colloque "Faire Campagne ${ }^{1}$ » avait l'ambition de réinterroger la notion de ruralité, en l'inscrivant dans le champ de la géographie sociale. Dans cette perspective, les différents articles proposés dans ce dossier invitent à modifier les modes de pensée et les grilles de compréhension des sociétés et des espaces ruraux.

Les différentes catégories spatiales à fondement statistique, dont certaines sont héritées du milieu du XIX siècle, n'offrent plus une vision juste des nouvelles réalités rurales. À partir de l'exemple des campagnes du Québec, Bruno Jean et Stève Dionne démontrent que le poids des représentations et des discours est déterminant dans l'image des campagnes, portées par ses acteurs et interprétées par la société tout entière. En présentant la ruralité comme une construction sociale en perpétuelle évolution, ils soulignent l'incontournable dimension idéelle et sociale de sa définition. De même, Pierre Couturier, en s'intéressant aux espaces ruraux marginaux et fragiles du Forez, montre la nécessité de construire des définitions de plus en plus fines, s'appuyant tout aussi bien sur la dimension matérielle des espaces considérés, que sur les représentations sociales, le système de valeurs, la charge symbolique des groupes humains qui y vivent et les pratiquent. Ces travaux révèlent la nécessité d'élargir les investigations sur les espaces ruraux vers une dimension qualitative plus sensible, et ce faisant, de participer à la redéfinition de nouvelles catégories spatiales.

La distance à la ville et la plus grande mobilité des populations produisent l'émergence d'un continuum spatial du pôle urbain vers les périphéries rurales, mais concourent simultanément à l'accentuation des différenciations internes aux espaces ruraux et à une plus grande hétérogénéité des sociétés rurales. Les travaux de Rodolphe Dodier sur les ménages périurbains analysent l'ar- 
ticulation des différents espaces de vie des populations résidant à la campagne et travaillant ou consommant à la ville. L'apparente homogénéité du terme générique « périurbain » masque en fait une très grande diversité des modes de vie et des identités sociale et spatiale des habitants. Il montre que les modes d'habiter sont certes influencés par les cycles de vie des familles, les conditions socio-économiques des ménages mais dépendent également des caractéristiques géographiques des espaces et reflètent des représentations et des attentes variées vis-à-vis de la campagne. L'article de Didier Desponds confirme ces observations, en montrant comment la création du Parc Naturel Régional du Vexin modifie le profil social des populations, indépendamment du projet de départ. Le phénomène de gentrification qu'il décrit est soutenu par un discours qui privilégie l'environnement et un passé rural idéalisé. La contribution de Monique Poulot et Thérèse Rouyres sur les campagnes franciliennes nous renvoie aux mêmes problématiques. L'espace rural est l'objet de multiples usages, pratiques et représentations, sous le jeu de plusieurs agents et acteurs en présence, parfois difficiles à concilier et aboutissant à des concurrences foncières et fonctionnelles. Les activités agricoles, pourtant économiquement puissantes en Île-de-France, résistent difficilement au développement résidentiel périurbain. Leur pérennité passe par l'adhésion du monde agricole aux attentes des habitants, promoteurs d'une vision idéalisée des campagnes, associant protection de la nature, entretien d'un décor paysager et production de qualité.

Ces articles confirment que la campagne vit aujourd'hui un tournant de son histoire. Suite aux métamorphoses sociales, économiques, territoriales des espaces ruraux, l'image de la campagne connaît un retournement total. Hier symbole d'enfermement social et d'archaïsme, la campagne est aujourd'hui un symbole de liberté associée à l'espace, un symbole de qualité de vie liée tant à l'environnement paysager qu'à la petitesse des communautés humaines supposées offrir un lien social nourrissant, un symbole d'une nouvelle «way of life » recherchée notamment par les étrangers d'Europe du Nord qui affluent dans les campagnes françaises ${ }^{2}$. Cette attraction des campagnes s'opère sans aucune politique volontariste de grande ampleur des espaces ruraux euxmêmes. Et, les conséquences sur les sociétés et les territoires locaux sont encore mal mesurées. Mais, les agglomérations urbaines elles-mêmes ne s'y trompent pas, en tentant aujourd'hui de préserver l'agriculture ou tout au moins un décor rural sur leur territoire, visant à repenser leurs relations à la campagne.

Cette attraction nouvelle des campagnes nécessite de repenser les définitions rurales, fondées en France essentiellement sur les mouvements pendulaires de travail et sur la distinction « rural sous influence urbaine » ou « rural isolé ». Au-delà des définitions, se posent des questions de mesure, d'analyse et d'interprétation. Car, certains mouvements de migrations vers la campagne ne répondent pas aux modèles économiques classiques. Si les observations de terrain se multiplient, les concepts restent à construire et cela nécessite un changement d'échelles, aux articulations d'autant plus délicates, que les données qualitatives sont difficiles à généraliser. Enfin, la représentation graphique et cartographique de ces nouvelles réalités rurales, associant des objets non-matériels, le poids des représentations, les jeux d'acteurs, constituent un réel défi pour la géographie.

2. La commission de Géographie Rurale du CNFG a organisé un colloque franco-britannique sur cette question à Vichy en mai 2006 